\title{
A Mental Models Study of Hurricane Forecast and Warning Production, Communication, and Decision-Making*
}

\author{
ANN BOSTROM \\ University of Washington, Seattle, Washington \\ Rebecca E. Morss, Jeffrey K. Lazo, Julie L. Demuth, and Heather Lazrus \\ National Center for Atmospheric Research, Boulder, Colorado \\ REBECCA HUDSON \\ Southwest Gas Corporation, Phoenix, Arizona
}

(Manuscript received 28 April 2015, in final form 22 November 2015)

\begin{abstract}
The study reported here explores how to enhance the public value of hurricane forecast and warning information by examining the entire warning process. A mental models research approach is applied to address three risk management tasks critical to warnings for extreme weather events: 1) understanding the risk decision and action context for hurricane warnings, 2) understanding the commonalities and conflicts in interpretations of that context and associated risks, and 3) exploring the practical implications of these insights for hurricane risk communication and management. To understand the risk decision and action context, the study develops a decision-focused model of the hurricane forecast and warning system on the basis of results from individual mental models interviews with forecasters from the National Hurricane Center $(n=4)$ and the Miami-South Florida Weather Forecast Office $(n=4)$, media broadcasters $(n=5)$, and public officials $(n=6)$, as well as a group decision-modeling session with a subset of the forecasters. Comparisons across professionals reveal numerous shared perceptions, as well as some critical differences. Implications for improving extreme weather event forecast and warning systems and risk communication are threefold: 1) promote thinking about forecast and warning decisions as a system, with informal as well as formal elements; 2) evaluate, coordinate, and consider controlling the proliferation of forecast and warning information products; and 3) further examine the interpretation and representation of uncertainty within the hurricane forecast and warning system as well as for users.
\end{abstract}

\section{Introduction}

Research on hurricane perceptions and evacuation decisions has expanded considerably in the last decade (e.g., Dash and Gladwin 2007; Huang et al. 2012, 2016; Meyer et al. 2013; Rice 2014; Sherman-Morris et al. 2011; Wolshon et al. 2013), but there is as yet little understanding of hurricane forecasting, warning, and decision-making as a

\footnotetext{
* Supplemental information related to this paper is available at the Journals Online website: http://dx.doi.org/10.1175/WCAS-D15-0033.s1.

Corresponding author address: Ann Bostrom, Daniel J. Evans School of Public Policy and Governance, University of Washington, P.O. Box 353055, Seattle WA 98195-3055.

E-mail: abostrom@uw.edu
}

system. One approach to learning how to improve hazard warning systems is to develop an integrated understanding of multiple stakeholders' roles in warning production, communication, and decision-making processes. Two National Research Council (NRC) reports, Completing the Forecast and When Weather Matters, highlighted the importance of understanding the perceptions and needs of multiple users of weather forecast and warning information, and of integrating this understanding into forecast and warning production (NRC 2006a, 2010). Hence, a fuller understanding of the behavior of key organizations involved in creating, communicating, and using warning information, such as the National Weather Service (NWS), mass media organizations, and local emergency management agencies, is warranted. Although it seems reasonable to hypothesize that weather forecasters, public officials (PO), and the broadcast media (BR) have different 
perceptions and needs with respect to extreme weather information, this has been little studied [see Anthony et al. (2014) and Demuth et al. (2012) for exceptions].

The sheer volume of forecasts and warnings in Hurricanes Katrina and Sandy also suggests the need for additional systematic research such as that presented in this paper. During Katrina's progression through Louisiana from Buras to the Mississippi border, the National Hurricane Center (NHC) issued 35 weather advisories, including five hurricane watches and warnings and over 10 tropical storm watches and warnings, and Weather Forecast Offices (WFOs) issued additional products. In Sandy, the NHC and WFOs issued over 500 different forecast, warning, and advisory products; the NHC alone issued 12 different communication product types and over 300 graphical products. ${ }^{1}$ These estimates are not comprehensive; during a typical hurricane, NWS generates many additional products, such as flash flood warnings, tornado warnings, and impact graphics. Further, many public officials, broadcast media personnel, private sector forecasters, and others create and disseminate their own hurricane forecast and warning information. And yet, in this sea of information available as a hurricane approaches the U.S. coast, some members of the public still misunderstood or failed to receive a key message in Katrina, Sandy, and other recent hurricanes: the potential risk that storm surge posed to life and property in at-risk coastal areas (e.g., Eisenman et al. 2007; Morrow et al. 2015; Morss and Hayden 2010; NOAA 2013). Thus, it is critical to incorporate into the forecast development process a more comprehensive understanding of what aspects of extreme weather risks various intermediaries, stakeholders, and citizens need to know about but do not, as well as deeper expertise on risk communication and decision-making. Otherwise, U.S. and international efforts to improve the communication of weather-related impacts and risks (e.g., Brunet et al. 2015; NOAA 2011; NRC 2006b; NRC 2010; Tierney et al. 2001) will not realize their potential, and may even be ineffective.

In this spirit, the study reported here explores how to enhance the use and value of forecast and warning information by examining the entire hurricane warning system, extending prior research that is focused on the value of extreme weather forecasts (Freebairn and

\footnotetext{
${ }^{1} \mathrm{NHC}$ data were obtained from the NHC Tropical Cyclone Advisory Archive (http://www.nhc.noaa.gov/archive/2012/SANDY.shtml). Additional WFO data come from http://mesonet.agron.iastate.edu/ cow/. Note that the product counts include updates. So, for instance, a WFO might issue the first coastal flood warning at 0500 local time on 28 October and then issue 18 updates to that product at subsequent days/times. Each of those updates is included in the product count because they usually include new information, and so this is a conservative estimate.
}

Zillman 2002; Katz and Murphy 1997; Lazo 2010; Lazo et al. 2010; Letson et al. 2007; Mylne 2002; Pielke 1997). The study also builds on the rich history of prior research on decision-making under uncertainty and risk judgment and communication in weather and other extreme event contexts (e.g., Doswell 2004; Downton et al. 2005; Joslyn and LeClerc 2012; Morss et al. 2008a; Murphy et al. 1980; Stewart et al. 1997). To advance the field methodologically and conceptually, the study adds a decision-analytic, systematic, multidisciplinary perspective to the body of empirical research on warning communication, use, and value, particularly in extreme weather events.

The paper focuses on key professional actors in the hurricane forecast and warning system-NWS forecasters, public officials, and broadcast media-and their interactions. Data collection methods include semistructured but open-ended interviews, which allow study participants to convey their own ideas about the structure and content of forecast and warning processes, participants in those processes, and the interactions of these, which are together referred to here as the forecast and warning system (see below). Our aims were fourfold: 1) to study the warning system holistically, with an emphasis on how informationincluding information on uncertainty-is created, interpreted, and used in decision-making by forecasters, public officials, and media organizations; 2) to identify commonalities and variations in information preferences and use across different professionals; 3 ) to explore more extensively the decision processes and mental models that underlie behavior with respect to warnings for extreme weather events; and 4) to develop guidance for improving warning system effectiveness that is informed by integrated multidisciplinary research and stakeholder feedback. In companion papers, we explore these research questions for flash flooding (Lazrus et al. 2016; Morss et al. 2015).

Section 2 of the paper describes our qualitative data elicitation and coding methods, as well as the analytical approach used to develop a decision model of the forecast and warning system and to quantify reliability and findings. Section 3 discusses the decision model as a whole, as well as each component of the hurricane forecast and warning system in more detail. Section 4 describes interviewees' perspectives on uncertainty in the system. Macro similarities and differences among professionals are explored in section 5 using a cluster analysis. In section 6 we summarize implications of the analysis for improving the hurricane forecast and warning system and future research.

\section{Methods}

\section{a. Sample}

The sample consisted of 19 professionals ( 8 NWS forecasters, 5 broadcasters, and 6 public officials) from the 
hurricane-prone area of Miami-Dade County, Florida. These professional groups were selected because, as discussed in Demuth et al. (2012) and section 3, each plays an important role in the hurricane forecast and warning system. Demographic questions were asked separately to preserve confidentiality; 15 of the 19 interviewees returned the demographic questionnaire. Recruitment was comprehensive, with repeated efforts to contact all members of the targeted professional groups in Miami-Dade, but time constrained because of the approaching onset of hurricane season.

The study included two groups of NWS forecasters: four hurricane specialists with the NHC and four forecasters with the Miami-South Florida WFO. The three NHC forecasters who returned the demographic questionnaire each had at least 17 years of experience forecasting at $\mathrm{NHC}$, and each had issued at least two hurricane warnings in the previous two years (note that only $\mathrm{NHC}$ forecasters can issue hurricane warnings). All had personally experienced a hurricane. One of the NHC interviews was abbreviated because of time constraints and so was excluded from quantitative analyses. The four WFO forecasters had 3-8 years of experience forecasting in the Miami-Dade area. Three of the four had personally experienced a hurricane. All of the NHC and WFO forecasters held bachelor's degrees in meteorology or atmospheric sciences, and five also held graduate degrees in these subjects.

The five broadcasters worked at local news stations (TV and radio), four as on-air meteorologists and one as station manager. Of the three broadcasters who returned the demographic questionnaire, two had fouryear college degrees, one in journalism and another in meteorology, and the third had a master's degree in speech. The three had 18-56 years of experience in broadcast media, and each had at least 5 years in their current employment in Miami. All had personally experienced a hurricane.

The six public officials worked at various government agencies involved in hurricane warning decisions, including a county and a state emergency management office and city and county law enforcement organizations. An additional public official participated in one of these interviews. Among the four who returned the demographic questionnaire, educational experience varied from some college to a master's degree; two had degrees in public administration. Three of the four had 20 or more years of experience as public officials dealing with hurricanes; two had worked in their current job for two years or less, and the other two had worked in their current jobs for 21 and 34 years, respectively. All of the public officials had personally experienced a hurricane.

\section{b. Mental models elicitation and analysis}

Mental models risk communication studies following Morgan et al. (2002) include initial decision modeling with domain experts and decision analysts, followed by semistructured interviews with stakeholders and with others who might receive messages or be involved in communications. Like some other semistructured interviewing techniques, mental models interviews strive to elicit people's beliefs in their own words and format. The intended advantage of mental models interviews for a study such as that discussed here is to elicit causal thinking about the hazardous process and related risk mitigation decisions. Details of the mental models approach along with the remaining interview, survey, and communication design and evaluation steps of mental models risk communication studies are described fully elsewhere (Bostrom et al. 1992; Bruine de Bruin and Bostrom 2013; Morgan et al. 2002).

In most previous studies, the decision modeling has involved literature reviews, expert elicitations, and other approaches, but typically not mental models interviews (Wood et al. 2012). In the present study, steps 1-3 below comprise this decision modeling.

The mental models research methodology employed in this study consisted of four main steps:

1) conducting individual mental models interviews with each professional;

2) conducting a group decision-modeling session to develop an initial model of decisions in the hurricane forecast and warning system and corresponding coding scheme;

3) coding individual interviews with reference to the group-generated decision model to content-analyze the data, augmenting the model as necessary; and

4) analyzing the output of the coding to assess commonalities and differences among interviewees.

The interviews and group session were audio-recorded, professionally transcribed verbatim, and quality-assured by comparing random samples of audio to transcriptions prior to analysis. Implementation of each step of the four-step methodology for the present study is described in more detail in the remainder of this section.

\section{1) INDIVIDUAL INTERVIEWS}

The individual interviews with each professional elicited interviewees' mental models of hurricane risks and warning decisions through a semistructured, open-ended question and prompting process that encouraged participants to report their beliefs and conceptions without interviewer biases or constraints. The interviewer began with the prompt "Tell me about hurricanes," then followed 
up on each major concept mentioned by the interviewee. The interviewer subsequently asked a series of increasingly structured questions about factors affecting the occurrence of hurricanes in Miami-Dade (exposure), risks from hurricanes (effects), and actions that can or should be done to mitigate risks ${ }^{2}$ from hurricanes (mitigation); these topics follow the causal structure of hazardous processes outlined in Morgan (1993) and Hohenemser et al. (1983). For example, with regard to exposure, interviewees were asked "What do you think determines whether a hurricane impacts Miami-Dade or not?", followed by neutral prompts, then the question "Are there particular times when a hurricane is more likely?" Effects questions included "What risks are there from hurricanes?", followed by "What might happen to a person who was in a hurricane?" and "What might happen to land or property impacted by a hurricane?", as well as additional neutral follow-up prompts, and "Do any other effects of hurricanes come to mind?" After a set of open-ended questions about reducing risks from hurricanes, interviewees were asked a few risk comparison and experience questions, as well as about where people might seek information about hurricanes. Interviewees were then asked to think back to a recent hurricane or hurricane warning that they had professionally experienced and were asked questions about influences on their decision-making in that context.

In the forecaster interviews, the individual forecasters were then asked to create an influence diagram ${ }^{3}$ of their conceptions of hurricane forecast and warning decisionmaking. To structure the diagramming exercise, we asked forecasters to write down each of the key factors that influence their hurricane warnings decisions on individual sticky notes [a variant on the assembly method described in Morgan et al. (2002)]. They were then provided a short lesson about influence diagrams along with a handout that illustrated the basic components and an example, and then they were asked to arrange the factors they had identified into an influence diagram. Forecasters were asked to think aloud as they created

\footnotetext{
${ }^{2}$ Although the term mitigate may be used by emergency managers to reference actions taken before an emergency that will be protective in the event of said emergency, the term is here used in its ordinary sense of reducing or lessening risk, including by prevention.

${ }^{3}$ Influence diagrams are a tool used in the field of decision analysis to graphically represent decision situations (Howard and Abbas 2016). While they look like directed network diagrams, in formal influence diagrams specific rules and elements are used to structure values, objectives of a decision, and other influencessuch as stochastic events-on decision outcomes in a logical framework (Clemen and Reilly 2001). The individual forecaster influence diagrams differed substantially from one another.
}

the diagram. This addition to the forecaster protocol familiarized the forecasters with this type of diagram and provided them with a chance to share their thinking about the hurricane forecast and warning system as a whole.

The think-aloud data collected while forecasters constructed their individual influence diagrams were transcribed verbatim and content-analyzed as part of the interviews. At the end of the interview, each of the 19 interviewees also filled out a short written survey.

\section{2) Group DECiSION MODELING}

In the group modeling session, a subset of the forecasters developed a consensus influence diagram characterizing hurricane forecast and warning decisions and risk management, with a focus on the Miami-Dade area. The session included four NHC forecasters and one WFO forecaster and was facilitated by project team members. Paralleling the individual influence diagramming exercise, forecasters were first asked to list (on sticky notes) all possible components of the hurricane forecast and warning system, using a series of prompts about the risks and consequences of hurricanes; actions and information needed to reduce hurricane risks; goals of hurricane warnings; and their decisions related to developing and issuing hurricane warnings. Session participants then received a handout that explained the different elements of an influence diagram and were asked to collectively assemble the components they had identified into a hurricane forecast and warning decision model, depicted as an influence diagram (shown in supplement A in the online supplement; R. Hudson 2010, unpublished manuscript). Throughout the process of developing the model, the forecasters were asked to think aloud and discuss with each other. They were also prompted to imagine hurricanes of varying strengths, estimate key probabilities related to the accuracy of forecasts and the heeding of watches and warnings, and discuss the components of existing hurricane risk information and potential improvements in the communication and use of this information. The full group session protocol is provided in supplement $\mathrm{A}$.

\section{3) INTERVIEW CODING AND AUGMENTING THE DECISION MODEL}

The verbatim transcription of the group modeling session discussed in section $2 b(2)$ informed our initial refinement of the diagram developed by the forecasters in the group session. The resulting model then served as a starting point for content-analyzing the individual interview transcripts (i.e., coding the results by comparison with the decision model), which also involved iteratively applying and refining the decision model. The data coders were researchers or students who, prior to 


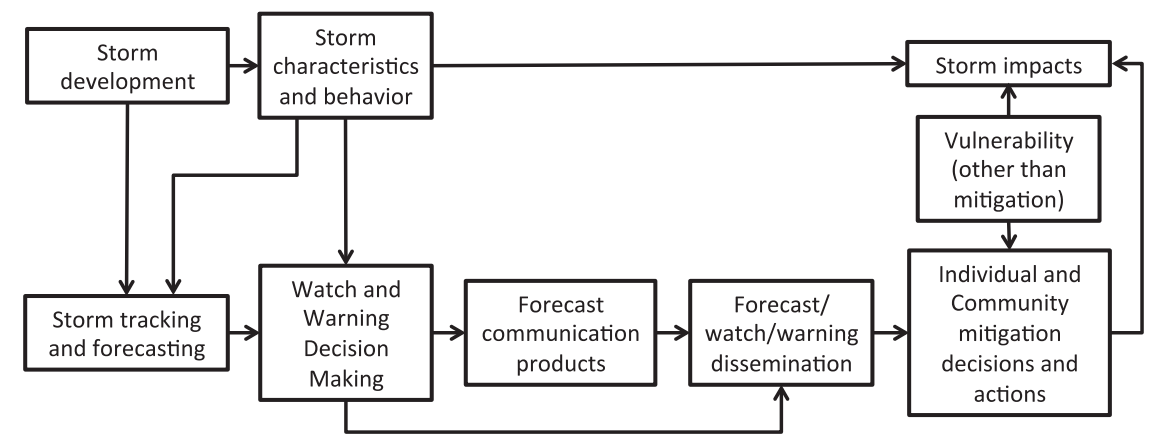

FIG. 1. Decision model of the Hurricane Forecast and Warning System, top level.

their involvement in this project, had limited expertise in meteorology or the hurricane warning system. A summary of our coding and content analysis approach is provided here; for details, including a discussion of intercoder reliability, see supplement B in the online supplement.

The initial coding scheme consisted of the pieces of the decision model, with each code representing a concept or proposition in the model. We then identified conceptual units in the individual interview transcriptions and coded these units according to the coding scheme, adding codes as needed to account for additional concepts mentioned by individual interviewees. Two to three coders independently coded the first interview of each group of professionals [NHC, WFO, $\mathrm{PO}$, and BR]. These initial coders then compared their coded interviews to generate coding agreement statistics and discuss any coding reliability issues that may have arisen. After this discussion, each coder independently recoded the first interview in each group of professionals. When satisfactory intercoder reliability was achieved for the interview sections and full interviews (supplement B), all remaining interviews were coded by at least one coder. The final coding scheme, which includes 189 different codes, then became the final decision model. The codes are hierarchical, such that some codes represent specifics or detailed variants of other codes to which they are subordinate in the scheme.

Thus, three methods inform the decision model: 1) individual mental models interviews, including an exercise in which forecasters think aloud as they diagram their own idea of the decision model; 2) group decision modeling, including an exercise in which a subset of the forecasters diagram forecast and warning decisions collaboratively; and 3) the researchers' own judgments in interpreting and formalizing the group and individual diagrams, guided by analysis of verbatim transcripts of the interviews and modeling exercises.
Through this process, the model-and hence the coding scheme-evolved substantially from the influence diagram developed during the group session, especially using the data from the forecasters. Although the model was refined further based on the broadcaster and public official interviews, only minor changes were made during these coding stages. Thus, the model remains forecaster-centric, as it was initially formulated by forecasters.

The final model represents the hurricane forecast and warning system, including the wide range of decisions made within the system and their influence on the subsequent impacts of hurricanes. The top level of the model is shown in Fig. 1.

\section{4) ANALYZING COMMONALITIES AND DIFFERENCES}

After completing the coding and quantitative analysis of codes mentioned by the professionals, we compared the relative occurrence of codes across different interviews and interviewee groups to 1) examine commonalities and differences in how interviewees thought about and discussed concepts corresponding to the same code and their interconnections and 2) identify and examine which codes (i.e., concepts) appeared more salient for some professional groups than others. For each code, we calculated the percent of interviewees in a given group of professionals who mentioned that code. Figure 2 shows the details of the model as well as these percentages for each code. The model is discussed in more detail below.

In addition, we calculated Hamann similarity measures for the professionals, based on whether or not they mentioned the same concepts, for all of the concepts in the coding scheme. The Hamann similarity measure is the probability that a concept has the same state (absence or presence) when compared between two professionals [present in both $(a)$ or absent from both $(d)$ ] minus the probability that a characteristic has different 


\section{(a)}

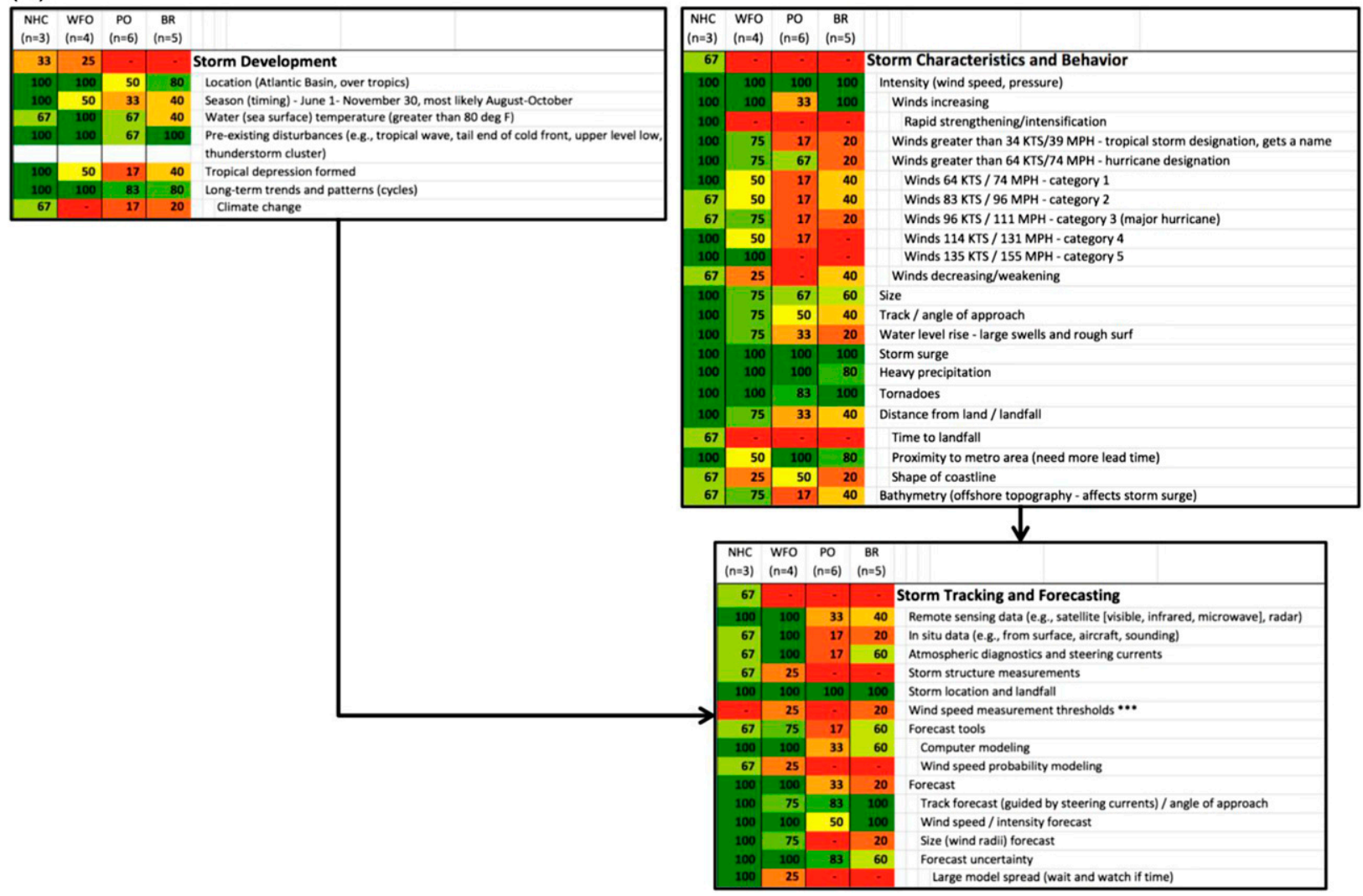

FIG. 2. (a) Storm development, storm characteristics and behavior, and storm tracking and forecasting sections of the full decision model of the Hurricane Forecast and Warning System, annotated to indicate the percentage of interviewees within each professional group (NHC, WFO, PO, and BR) who mentioned each concept in the model at least once in their interview. Percentages are color coded from red (concept was mentioned by no interviewees in that group) to dark green (mentioned by all interviewees in that group). (b) Watch/warning and related decision-making and forecast/watch/warning and related communication products sections of full model. (c) Forecast/watch/warning dissemination, individual and community mitigation actions and decisions, vulnerability, and storm impacts sections of full model.

states in the two items [present in one $(b)$ and absent from the other $(c)]$ :

$$
\operatorname{Hamann}(x, y)=[(a+d)-(b+c)] /(a+b+c+d) .
$$

Hamann similarity ranges from -1 to +1 and is monotonically related to other similarity measures (Holley and Guilford 1964). We calculated Hamann similarity between all possible pairs of professionals, then clustered on Hamann similarity.

\section{Results}

Our analysis identified many commonalities in how forecasters, broadcasters, and public officials understand hurricane risks, consistent with their professional roles and the institutionalization of hurricane risk management. Also evident are striking differences, some of which highlight opportunities for improving the hurricane forecast and warning system.

\section{a. Hurricane forecast and warning system interactions, decisions, and influences}

Before exploring piecewise the hurricane forecast and warning system that emerged from the interviews, we present a roadmap of the decision model (shown in Fig. 1), followed by a brief synopsis of the roles of and interactions among the professionals in the system. Although the overview begins with storm development and proceeds linearly, it is important to note that the professionals in the system recognize that risks are a function of social and individual choices (Tierney 2014); for example, the interviews reveal that professionals are proud of the benchmark building codes in Miami, and they comment that people have the option of moving away to escape hurricane risks. 
(b)

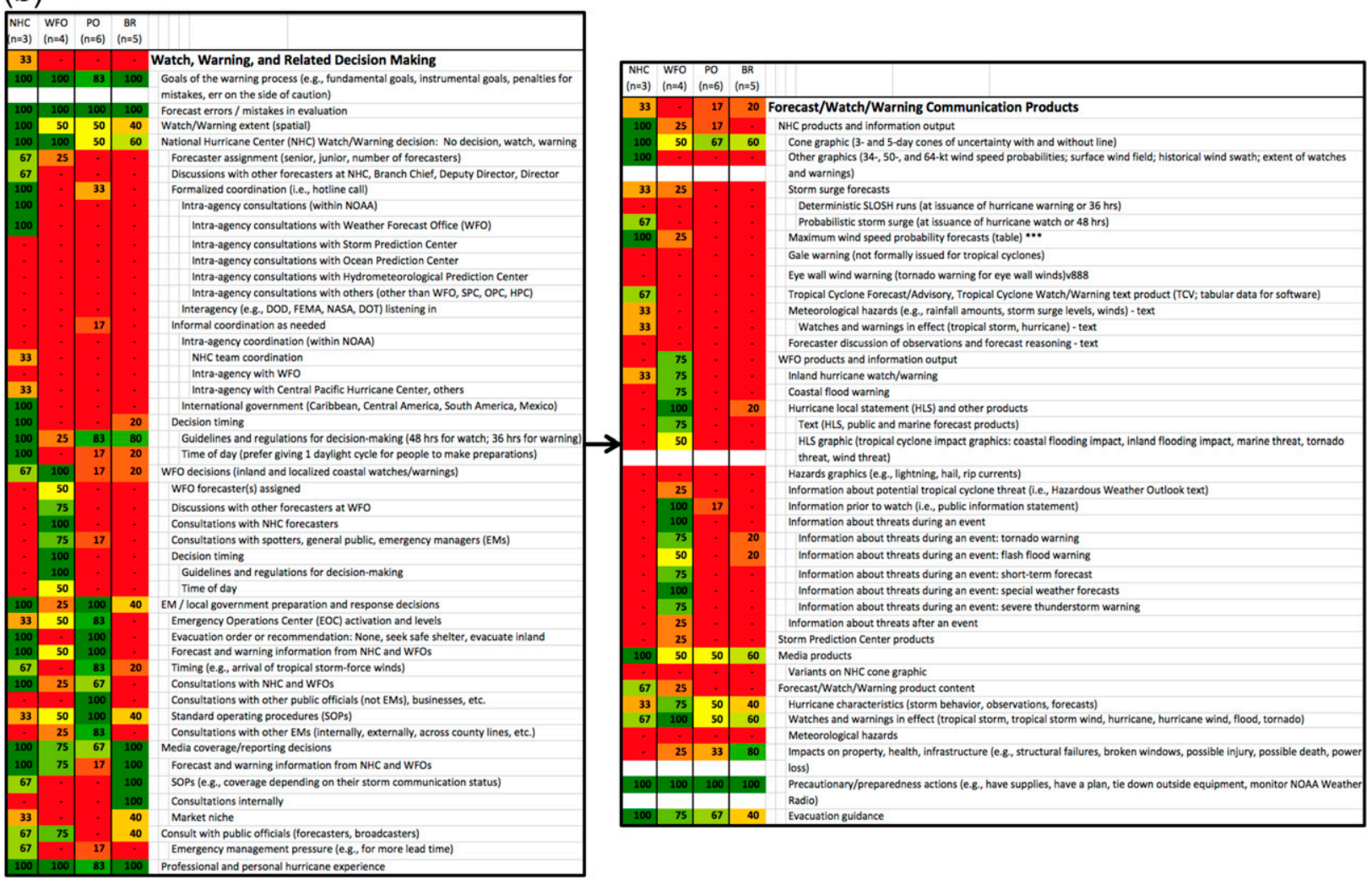

FIG. 2. (Continued)

Beginning at the top left of Fig. 1, conditions that initiate storm development affect the characteristics and behavior of the storm. Storm development, characteristics, and behavior are captured by, and thus influence, storm tracking and forecasting. Based on observations and forecasts, official guidelines, consultations with others, and other factors, professionals make decisions about whether and how to provide watches and warnings and how to communicate and disseminate the forecast and warning information. This information, along with vulnerability factors (e.g., population size and density, building preparedness), influences individual and community actions to mitigate the impacts of storms. These mitigating actions and decisions shape community resilience, which, together with the storm characteristics and behavior, determine the human, physical, social, and economic impacts of the storm.

NHC forecasters' primary role in the hurricane warning system is to monitor the east Pacific and Atlantic basins, including the Caribbean Sea and the Gulf of Mexico, and to issue tropical cyclone forecast products, including watches and warnings. WFO forecasters are responsible for daily weather forecasting for a smaller area (Miami and South Florida in the case of the Miami WFO). When a hurricane threatens, WFO forecasters issue localized forecast products for hurricane-related hazards, including, as needed, tornado and severe thunderstorm warnings, as well as flash flood watches and warnings as part of daily weather forecasting responsibilities. WFO forecasters are also consulted for their regional knowledge by the NHC during their hurricane warning process.

The NHC and WFO forecast and warning information is provided to broadcasters, who evaluate it using their own knowledge and other information (e.g., from their weather vendors). Broadcasters can also obtain information about warning response (such as evacuation recommendations and shelter openings and closings) from public officials. They then make decisions about how to present this collection of forecast and response information to their audiences.

Public officials receive information from and exchange information with the NHC and WFO through several mechanisms, including NWSChat and WebEOC, both of which are information management systems. They also discussed monitoring popular social media, such as Twitter or Facebook, and forecasts from other 
(c)
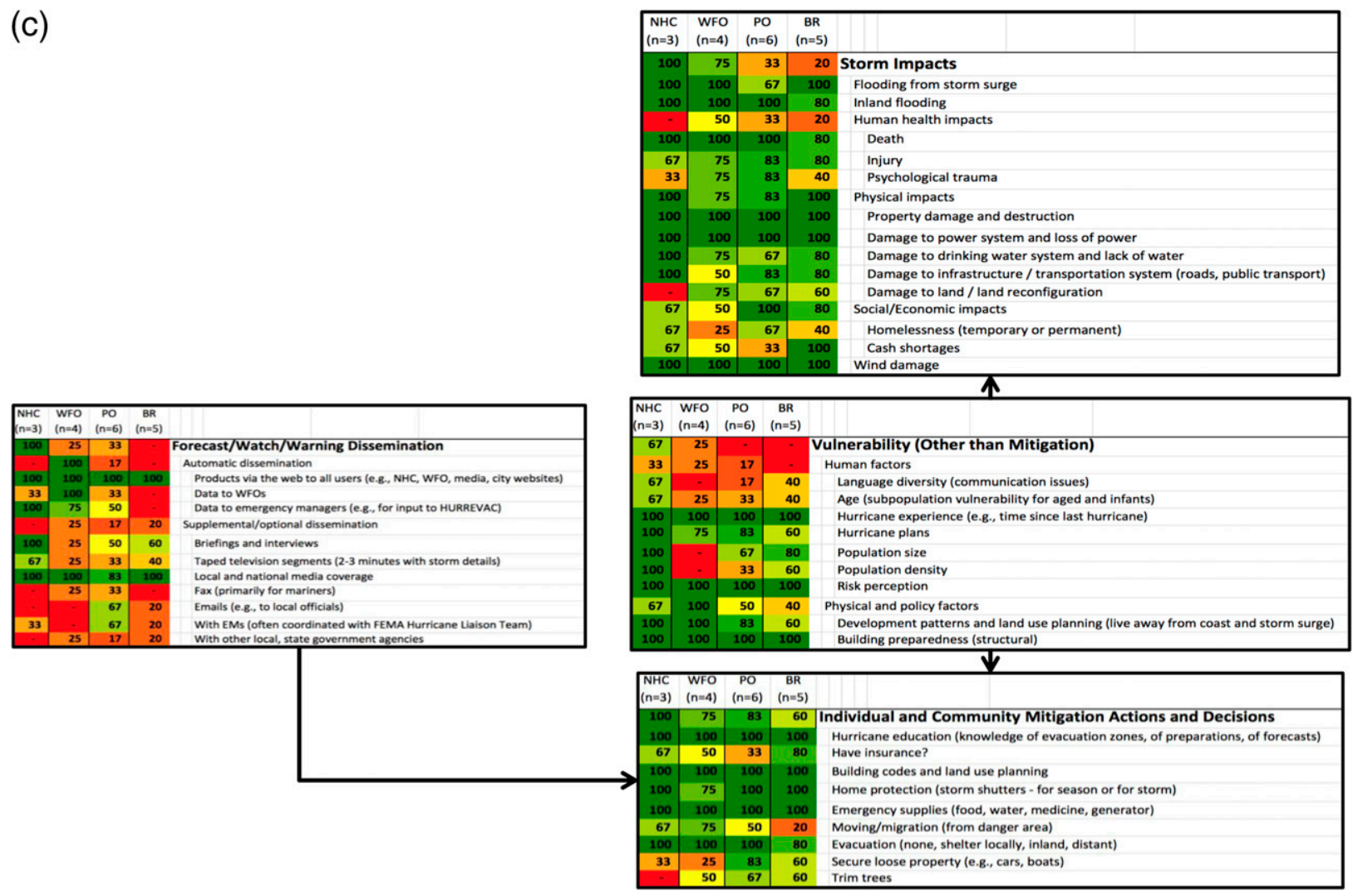

FIG. 2. (Continued)

weather information providers, such as broadcast media and AccuWeather. They use this information to make hurricane preparation and response decisions, such as whether to order or recommend evacuations, close schools or roads, and open shelters. These decisions are aided by decision support software (such as HURREVAC) and detailed incident action plans, and they are made in collaboration with other local and state agencies and partners in their Emergency Operations Center (EOC). Public officials also communicate about hurricane threats and preparations with targeted public audiences (such as transients and atrisk subpopulations) as well as with the general public in their communities.

According to the public officials we interviewed, overall, the interactions in the Miami-Dade hurricane forecast and warning system exemplify a good partnership (see also Demuth et al. 2012):

There is a very good partnership there between local emergency management officials and the weather, and it goes all the way down to the Municipal level and then up to the Feds. But when that stuff starts coming, your local National Weather Service Office is really who is providing that information with that local context. So that stuff begins to come out and as it looks more and more like that the particular area you are in, so say Miami-Dade is going to be impacted there will be conference calls, there will be specific weather briefings, there will be press briefings to the public as it looks closer and looks like the impact is going to be more real. So really what determines you know what sort of what is out there is both a very strong partnership with the Weather Service and then a public who is paying at least a little bit of attention to it. Because you also have a very good partnership with your media weather, your local media meteorologist. (PO1) ${ }^{4}$

As we discuss in the remainder of this section, however, a few challenges and mismatches in the system remain.

\section{1) STORM DEVELOPMENT, CHARACTERISTICS, AND BEHAVIOR}

Many of the professionals discussed storm development in terms of hurricane formation over warm, tropical, and subtropical waters (for Miami, in the tropical Atlantic)

\footnotetext{
${ }^{4}$ Quotes are attributed by the category of interviewee (NHC, $\mathrm{WFO}, \mathrm{PO}$, or BR) and number of interviewee in that category. For example, PO1 is the first public official interview.
} 
(NHC, 100\%; WFO, 100\%; PO, 50\%; BR, 80\%). ${ }^{5}$ Interviewees noted that hurricane formation varies interannually and that there are considerable uncertainties about the factors determining these variations.

The meteorological disturbances that influence storm development, such as tropical waves, were also mentioned by most interviewees (NHC, $100 \%$; WFO, $100 \%$; PO, 67\%; BR, 100\%). This includes, for some, watching meteorological disturbances since they may develop into a hurricane. As one broadcaster noted, "even if there is just a low pressure system in the Caribbean, that becomes like the lead story on the newscasts down here. It hasn't even developed into anything. ... But it could become a tropical depression, which means it could become a tropical storm, which means it could become a deadly category 5 hurricane" (BR5). The professionals also discussed the influence of meteorological conditions. As an NHC forecaster described, "we use the analogy here a lot that the hurricane's like a cork in a stream; that the hurricane is a cork, and the atmosphere is the kind of river of air that it's moving in. It's steered by a lot of largerscale features in the atmosphere" (NHC1). Thus, for the $\mathrm{NHC}$, WFO, and broadcast professionals, anticipating and monitoring hurricane formation and behavior is critical for storm forecasting [section 3a(2)].

Across the groups, professionals generally agreed that certain aspects of hurricane characteristics and behavior are important components of hurricane risk. All of the professionals discussed high wind speeds associated with hurricanes, and most discussed increasing winds as a characteristic of hurricane development and intensification. In addition, nearly all mentioned tornadoes (NHC, $100 \%$; WFO, $100 \%$; PO, $83 \%$; BR, $100 \%$ ), as well as heavy precipitation (NHC, 100\%; WFO, 100\%; PO, $100 \%$; BR, $80 \%$ ) that can contribute to flooding.

All professionals also mentioned that hurricanes can cause storm surge, referred to by a few professionals as tidal surge or storm tide (to account for the combination of hurricane-induced surge and high tide). Professionals did not all discuss storm surge risks in the same way; for example, one public official focused primarily on beach erosion associated with storm surge (i.e., surge impacts),

\footnotetext{
${ }^{5}$ Results are presented as percentage of interviewees in each group that mentioned a code, in this order: $\mathrm{NHC}$ forecaster $=\mathrm{NHC}$ (out of three, although quotes were examined from all four NHC interviews), WFO forecaster $=\mathrm{WFO}$ (out of four), public official $=$ PO (out of six), and broadcaster $=$ BR (out of five). While the samples are small, so are the numbers of these types of experts in a given geographic area; thus, we have chosen to present relative information (within a professional group) rather than the absolute numbers. All quotes are verbatim, with the exception that we removed "um" and "you know," and in a few cases, interjected "okay" remarks from the interviewer.
}

and several professionals commented that surge was a greater risk on the Gulf coast than in Miami-Dade (i.e., surge exposure). Nevertheless, most professionalsespecially forecasters-discussed storm surge as one of the greatest, if not the greatest, risks posed by hurricanes, especially to human life (see example quotes in Fig. 3). As one broadcaster explained, "well, everybody always thinks horrible wind, you know that the high winds are what causes the most destruction, although again if you have listened to any of the experts it is the tidal surge, the storm surge which is the waves and all the water that is pushed ashore ahead of the system. And the flooding can cause a lot more destruction and a lot more economic impact potentially than the wind can" (BR5). Because storm surge can pose significant threats to human life, it is often a primary reason for evacuations.

Overall, professionals from different groups emphasized similar aspects of hurricane development, characteristics, and behavior, although with some variations in emphasis. However, ours and related research suggests that there is a disconnect between professionals and many members of the public on the relative importance of storm surge risks (Morrow and Lazo 2014; Morrow et al. 2015; Morss and Hayden 2010). We discuss the professionals' views of storm surge risks further in section $3 \mathrm{a}(6)$, and in a companion paper we examine this potential disconnect in further depth using mental models interviews conducted with members of the Miami public (A. Bostrom et al. 2016, unpublished manuscript).

\section{2) STORM OBSERVING AND FORECASTING}

All of the forecasters and some of the other professionals discussed tracking (or observing) storm characteristics and behaviors using remote sensing (e.g., satellites, radars) and in situ observing platforms (e.g., dropsondes, buoys, ships, reconnaissance aircraft). These tools provide data about temperature, pressure, winds, and other parameters that are used to analyze the hurricane's characteristics and its environment (e.g., steering currents). These data are fed into statistical and dynamic models to produce deterministic and probabilistic (ensemble based) forecasts of the hurricane and associated hazards, which professionals-especially the forecasters and broadcasters- then use (in combination with observations and other information) in their forecast- and warning-related decision-making [section $3 \mathrm{a}(3)$ ].

All of the forecasters and most of the public officials and broadcasters mentioned forecast uncertainty (NHC, $100 \%$; WFO, $100 \%$; PO, $83 \%$; BR, $60 \%$ ), which is discussed further in section $3 \mathrm{a}(7)$. Further, some professionals discussed how forecasts have improved in recent decades, in part because of advances in observational technologies. Several also noted that these observational 


\section{Code 11500: Storm surge}

NHC1: "I mean that's the main reason why we want people evacuated - from storm surge."

NHC3: "One of the reasons we have the big evacuation and response programs around the United States is to get people out of the way of the surge. ... if your house is falling down around you in high winds, you can, chances are you can find a safe room somewhere in the house. You can't do that if there's 6 to 8 feet of water inside the house, which in some areas is a distinct possibility.

NHC4: "And then - so storm surge has the largest potential to kill the largest number."

WF01: "With a strong hurricane, the storm surge would be probably the second biggest risk, because of the high winds and the effect that's going to have on the - the magnitude of the surge right at the coast."

WF04: "Well, for sure the main threats out of this whole thing if it is to people first it is definitely storm surge."

BR1: "We have seen the pictures out of Katrina and some of the other more recent ones like Ike and we know that a storm surge can pretty much completely wipe clean areas where it strikes."

BR1: "I am putting storm surge first because I think it is the biggest threat to life. You know even though the storm surge in Miami-Dade County, the worst storm surges here are half of what they can be along the Gulf Coast [...] But still 15, 10 or 15 feet, if you don't leave the coastline you can drown and then, so therefore I think it needs to rank first."

P06: "From my classes I would say that the storm surge will be the worst, if it is really bad that is the worst thing that is going to happen here."

P04: "In Mississippi there was a lot more flooding and people drown based on you know the tidal surges, we don't have that big of an issue here. Although it could come, we are more concerned you know with the wind effects and the rain, so on and so forth."

FIG. 3. Illustrative quotes about storm surge.

advances and their wider use make hurricanes and their development visible to more people earlier in time, in ways that the professionals think influences people's risk judgments and decisions. For example, satellite imagery now conveys clearly what a full hurricane looks like and its approach, which was previously presaged only by rough surf and winds as the storm neared landfall. One NHC forecaster explained how satellite imagery has improved evacuation rates:

Before we had satellites and aircraft, people were looking for ways to see when a hurricane was coming, and probably number one is rough surf. Large swells starting to impact the coast. Water level rise.... Nowadays with the better technology of course we're monitoring them on satellite. Seeing satellite images. So we can certainly see beforehand that a storm is approaching, and I actually think that's one of the reasons why people ... do evacuate. It's because now they can see this monster looking storm on satellite image and start to say, wow, we should do something. Whereas, you know, before that it was when the wind started blowing. (NHC1)

This suggests that by influencing people's understandings and perceptions of storm risks, hurricane observations as well as forecasts can play a role in warning decision-making.

\section{3) WATCH, WARNING, AND RELATED DECISION-MAKING}

Based on the storm behavior and forecasts and other factors, professionals make decisions about whether and how to provide watches, warnings, or other alert information, and about how to use this information to help protect populations at risk. As the decision modeling 
revealed, this decision-making is both institutionally and procedurally complex (see Fig. 2). For example, NHC interviewees mentioned consulting with their supervisors and with WFOs when making watch or warning decisions. NHC forecasters noted that the senior specialist on duty makes the decisions about issuing hurricane-related watches or warnings, but in the case of multiple simultaneous events, junior forecasters may make such decisions as well. They also consult and coordinate with a wide variety of other agencies in the United States and internationally, through formal mechanisms such as hotline calls as well as informal mechanisms. Some decisions, such as specific geographical breakpoints for warning areas, are determined in coordination with other parties in advance of the hurricane season each year.

It is NWS policy that WFOs rely on the NHC forecast when making hurricane-related forecast and warning decisions. As a WFO forecaster explained, "we don't want to have two messages; we strictly follow [the NHC] forecast track. ...[R]eally, we just have a procedure to load in their new forecast and where it takes it across our area. [We make only] minor tweaks, not in the track or anything, just if there's any local effects" (WFO3). WFO forecasters also discussed consulting with multiple other professionals when making decisions, including NHC forecasters, other WFO forecasters, and emergency managers. Public officials (emergency managers) discussed using NHC and WFO information in their preparation and response decisions, as well as consulting with NHC and WFOs, other emergency managers and public officials (e.g., departments of transportation), and other parties (e.g., businesses). The broadcasters also discussed using information from NHC, WFOs, and public officials, as well as consulting with others within their media organization when making reporting and coverage decisions. Thus, the warning system involves many individuals and organizations interacting with each other in making interrelated decisions.

Along with the procedurally complex and interrelated nature of warning decision-making, each of the professional groups described organizational regulations and guidelines that influence their decisions. NHC and WFO forecasters discussed the formal rules and criteria that govern, for example, their timing for issuing certain products. They also discussed informal guidelines, such as issuing warnings early in the day when possible to "try to give [people] as much daylight preparation time as we can fit into our, into our criteria" (NHC3). Public officials discussed standard operating procedures "that detail what we do at certain points to prepare ourselves" (PO5), including timing of decisions with respect to the arrival of tropical storm winds. And broadcasters discussed organizational guidelines and procedures for how they cover a storm at different points in time during its approach, including the use of templates for hurricane reports and visuals and the role of management in determining when to go to round-the-clock coverage. As these examples illustrate, timing is an important aspect of decision-making for all of the professional groups interviewed.

Another common factor that influences professionals' warning-related decisions is their views of the goals of their decisions and the warning system (NHC, 100\%; WFO, 100\%; PO, 83\%; BR, 100\%) (cf. Demuth et al. 2012). The goals discussed include informing and protecting the public, as well as avoiding unnecessary public alarm, disruption, and financial costs. When deciding whether and when to issue watches and warnings and what geographical areas to cover, the NHC and WFO forecasters discussed watching and waiting to see how the situation evolves, but also erring on the side of caution, especially in more densely populated areas where more people are at risk and evacuation takes more time. As one WFO forecaster stated, "if it's over [the Miami metro area and] we're a little more on the fence like, for a severe [event], you know we'll tend to lean towards the side of caution here. If it's over the middle of the everglades where no one lives, if we're debating then we'll be like "well, we'll stay away from it until it intensifies"' (WFO3). Similarly, an emergency manager explained, "you have to err on the side of caution, so it is uncertain what is going to happen, but ... we always tell them prepare for the worst and hope for the best" (PO6). Broadcasters discussed weighing how much information to give their audiences; as one stated, "believe me, we err here on the side of too much warning or too much information, we would rather let you know if the atmosphere hiccups in the middle of the Atlantic" (BR3).

The inherently uncertain nature of hurricane evolution makes accurate forecasting a challenge. Recognizing this, all of the professionals mentioned errors in forecasting or evaluating a hurricane threat. For example, one public official observed that a hurricane "could be very unpredictable as far as its strength, its size, the destruction that it causes and even its path; you know, you can never predict the direction that a hurricane will actually go or how long it would stay" (PO2). Given these errors and the need to give people enough time to take action, forecasters often issue warnings for a larger area than will be affected. Further, forecasters remarked in several instances that some broadcasters overreact or "jump the gun" (WFO4) in reporting hurricane watches or warnings, or sometimes deviate from the forecasts produced by the NHC. When a hurricane changes directions or decreases in size or wind speed, these errors 
can lead to evacuations and preparations that turn out to be unnecessary. However, with lives at stake, some professionals appeared to see false alarms as a (necessary) corollary to making precautionary, potentially lifesaving decisions in the face of uncertainty.

Nearly all of the interviewees discussed relying on their professional and personal hurricane experience when making warning-related decisions (NHC, 100\%; WFO, $100 \%$; PO, $83 \%$; BR, $100 \%)$. Along with their professional warning experience, NHC and WFO forecasters discussed the influence of their personal experience with hurricanes on their understanding of hurricane impacts and preparations. Describing how experience influenced a specific warning decision, one WFO professional explained that, "because I have gone, I have gone through it, I experienced it, so I know what to expect and what people go through. So [this experience] beefs up ... what we call situational awareness" (WFO4). In addition to personal experiences such as growing up in the area, public officials mentioned the value of their past professional experiences in making decisions. For example, one discussed "learning from the events that we had in the past where we had trees down that have blocked major thoroughfares and arteries, and now we are better able to handle them from those experiences, we are better able to handle points of distribution. So, I mean there have been a lot of lessons learned and I think it has made us much better" (PO4). Broadcasters discussed how their experience helps them interpret forecast information and communicate about hurricane risks with their viewing audience. For example, one broadcaster (with decades of experience) explained "I think people do respect a great deal my knowledge and experience in these storms, to where they know that they can rely on a lot more insight than perhaps a normal TV station might give them in each one of these emergencies" (BR1). References to experiences of previous hurricanes were pervasive, suggesting that this is a major factor influencing warning-related decision-making in the Miami area.

\section{4) FORECAST COMMUNICATION PRODUCTS AND WATCH/WARNING DISSEMINATION}

Professionals' decisions as to whether and how to provide watches, warnings, and other alerts in turn affect what kinds of forecast and warning information is communicated and how it is disseminated. Our analysis suggests a few potentially important disconnects between the hurricane risk information produced and communicated and that received and used. As is evident from Fig. 2, NWS issues a number of hurricane-related forecast and warning products, but most appear to be salient only to those producing them. One NWS product, the uncertainty cone graphic, was mentioned by members of all professional groups interviewed (NHC, 100\%; WFO, 50\%; PO, 67\%; BR, 60\%). Otherwise, the NHC and WFO products discussed by the NWS interviewees were mentioned rarely or not at all by the public officials or broadcasters.

The analysis also revealed disconnects between the information content professionals are trying to provide and what intended audiences receive and use. Illustrating this and the previous point, an NHC forecaster discussing the different NHC products explained that "we issue things such as the cone graphic that shows the probable track of the center. We do issue, and not a lot of people use it and the general public may not necessarily understand it, but we do issue probability forecasts that describe the probability of tropical storm force $\left(\geq 34 \mathrm{kt} ; 1 \mathrm{kt}=0.51 \mathrm{~m} \mathrm{~s}^{-1}\right), 58 \mathrm{mph}(\geq 50 \mathrm{kt})$ and hurricane force $(64 \mathrm{kt})$ winds occurring at individual locations. If you really want to know your risk, that's the product to go to" (NHC1). Even though this forecaster believes that the probabilistic wind forecasts produced by NHC are more valuable than the cone graphic for evaluating risk, none of the public officials or broadcasters happened to mention these products; they focused on the cone graphic instead.

Another example of the disconnect between information provided versus used is the WFO Hurricane Local Statement (HLS), which one WFO forecaster described as "our biggest [product] talking about the hazards" associated with a hurricane (WFO3). The HLS was only mentioned by one non-WFO interviewee, a broadcaster. Moreover, this interviewee described the HLS as "unwieldy and long and confusing" and "difficult to read" for him, much less for people without meteorological training (BR2). This suggests that there are issues with the usability of NWS forecast information. Although this broadcaster commented on work underway to make NWS products more readable, and two WFO forecasters mentioned graphical products being designed to help improve WFO communication about hurricane hazards, limited progress has been made. More generally, many of the NWS and broadcaster interviewees expressed that they were not sure who used the information they provide or how, or how users interpret their products. For example, when asked who used the information he produced, one broadcaster responded "you hope everybody, but you know I would have no way of evaluating that."

Regarding hurricane forecast and warning information dissemination, our analysis identified more agreement among professionals. All of the interviewees discussed Internet-based dissemination, and nearly all discussed television and mass media dissemination. 
Professionals also discussed specialized software for disseminating and exchanging information, such as the NWSChat program that allows public officials and broadcasters to communicate directly with NWS forecasters. These common views of the different professional groups' roles and the channels they use for hurricane information dissemination likely contribute to the effectiveness of their partnership functions.

\section{5) VULNERABILITY AND INDIVIDUAL AND COMMUNITY MITIGATING ACTIONS AND DECISIONS}

In what has in other contexts been referred to as a reinforcing spiral, those who are vulnerable are likely to pay more attention to forecasts, watches, and warnings, which in turn may also remind people of their vulnerabilities and then trigger individual and social actions to mitigate the impacts of approaching storms. The professionals discussed vulnerability factors related to the built and social environment, such as development patterns, the resilience of structures, building codes, and population size and density, as well as human vulnerability factors such as hurricane experience, risk perceptions, and hurricane plans (Fig. 2).

Much of the professionals' discussions of ways to reduce hurricane risks focused on individual mitigating actions. Most discussed the importance of individuals protecting their homes, for example, by putting up shutters or plywood, to mitigate the damages a landfalling hurricane can cause to property, including roofs, windows, cars, and potentially the entire house (NHC, 100\%; WFO, 75\%; PO, $100 \%$; BR, 100\%). One public official noted that "hardening your home is going to be the [action] that is most influential and effective at [mitigating] hurricane risk." Many of the interviewees discussed home protections as actions they undertake as well as warn others about. Another important individual protective action is gathering supplies such as food, water, batteries, flashlights, and generators (100\% all groups). Public officials especially focused on the supplies nonevacuees should gather to be self-sufficient for at least $72 \mathrm{~h}$ but potentially as long as a week after a hurricane. For example, one public official discussed "mak[ing] sure that [people] have a plan in place, whether it is they need to evacuate [or] buy the necessary sustainable items to keep them [alive] for a 72-hour period ... [or] that they have fuel" (PO4).

In addition, all but one of the professionals emphasized the importance of evacuation as a protective action (NHC, 100\%; WFO, 100\%; PO, 100\%; BR, 80\%). However, the professionals differed somewhat in how they discussed evacuations. The NHC and WFO interviewees discussed hurricane evacuations in terms of the risks people face and ways to reduce physical risks resulting from hurricane exposure. For example, a WFO forecaster discussing building destruction commented that "the structure could collapse on them, so we are telling people [that are in] mobile homes or weak structures to go to open shelters to keep them safe", (WFO4). Public officials, on the other hand, focused more on the need for shelters, the economic impacts of running shelters, the need for people to plan evacuations, and their own roles in the evacuation process.

The professionals also mentioned community and larger-scale mitigating actions, including Miami-Dade's benchmark building codes, which were implemented in the wake of Hurricane Andrew, and the importance of state insurance. These discussions highlighted the value of Miami's stringent building codes, although professionals also mentioned older construction that does not meet code. A few forecasters and broadcasters brought up weather modification, noting that it is not a currently viable approach to reducing hurricane risks.

The commonalities across professional groups with regard to discussing vulnerabilities and mitigation illustrate their shared awareness that actions and decisions to address vulnerabilities to storm behavior can reduce negative consequences, including the physical, social, and economic impacts of a hurricane and its aftermath.

\section{6) STORM IMPACTS}

Professionals mentioned a variety of types of impacts resulting from the strong winds, heavy rain, and storm surge associated with hurricanes. All of the professionals discussed damage caused by hurricane-force winds. These are dangerous because of both the high wind speeds and the wind-blown debris-ranging from shingles to large metal panels to trees-that become dangerous projectiles, potentially damaging property in their path and injuring and killing people. As a public official explained, "the wind damage could be ripping out the roofs ... causing windows to fly out, to burst the windows, to uprooting trees which can cause [the] destruction of houses and buildings" (PO4).

Most professionals also mentioned that hurricanes can cause inland flooding resulting from heavy rain (NHC, 100\%; WFO, 100\%; PO, 100\%; BR, 80\%) as well as coastal flooding from storm surge (NHC, 100\%; WFO, 100\%; PO, 67\%; BR 100\%). A WFO forecaster explained that "the problem [with flooding] is it comes up while you have a hurricane, [and] nothing can drain back out to the ocean, so if you are picking up 10, 30 inches of rain throughout a hurricane then everything backs up on top of that." Such flooding damages roadways and can obstruct traffic even after hurricanes pass. In the case of storm surge, the professionals noted that the resulting flooding can cause widespread destruction 


\section{Code 12320: Human Injury}

WF01: "[A person who is in a hurricane] could be injured or killed."

BR1: "If you are in a protected home that was built recently under good codes you should be able to withstand the hurricane winds, but...if you are not, [there is always the risk of] walls or beams or things like that fall[ing] on you.

P02: "[T] he most severe [impact of hurricanes] would be definitely building collapse. Because then you end up with trapped victims."

P01: "You will have some flying debris, it could be small flying debris, it could be large giant pieces impaling folks."

BR3: “People make the mistake of, 'Oh, it's done, I will go outside.' Well, that is where they get into trouble. A tree limb falls on them, they will step on a live wire, [or] a big nail goes into their foot."

FIG. 4. Illustrative quotes about human injury.

and many deaths (Fig. 3). As one public official commented, "flooding is the two-headed monster. It can kill people, and [require] long-term recovery; it would be one of your big causes of damage."

Most professionals mentioned that hurricanes cause human injury (NHC, 100\%; WFO, 75\%; PO, 83\%; BR, $80 \%$ ) as well as death (NHC, 100\%; WFO, 100\%; PO, $100 \%$; BR, $80 \%$ ). NHC and WFO forecasters typically mentioned injuries or death as a general consequence of storms, whereas broadcasters and public officials were more likely to describe specifically how and what kinds of injuries could occur. The most commonly mentioned sources of injuries and death were vulnerable or poorly protected property; falling structures, such as buildings and trees; being trapped inside vehicles or buildings; flying debris, including large objects; and human error or risky behavior (see Fig. 4 for representative quotes). The professionals discussed death, both as a direct result of hurricanes and in the aftermath, and some also mentioned deaths resulting from storm preparation.

Some professionals identified storm surge as posing the most significant risk for loss of life from hurricanes. This is corroborated by recent research (Rappaport 2014). Andrew was the strongest recent hurricane to affect Miami. As one NHC forecaster noted, "we had a 17-foot surge in Andrew, although it was very localized. ... It didn't go very far inland. And the vast majority of the wind damage (sic) and almost all of the loss of life in Andrew was wind, not surge"; the forecaster went on to explain that "when it comes to killing people, surge is the biggest potential threat. Because even though southeastern Florida is not as vulnerable to surge as other parts of the country, we can get the high surges. We have a lot of people living right on the coastal surge zones" (NHC3). However, as discussed in section $3 \mathrm{a}(1)$ and is evident from Fig. 3, not all professionals agreed about the relative importance or likely consequences of storm surge in Miami.

Another type of hurricane impact discussed by the professionals is hurricane damage to infrastructure, especially damage to power systems and loss of power (100\% all groups), which can last for a few days or even months. Describing the impacts of loss of power, a broadcaster explained how "the mental fatigue plays in, especially when you are going you know three weeks, four weeks, five, you know two months without electricity, you haven't taken a warm shower in weeks and you know you are cooking out of a little hibachi in the backyard, and you have no air conditioning and it is the middle of summer." Downed power lines in yards and streets can also lead to disruptions and to deaths from electrocution, especially when there is flooding. Less often mentioned by professionals were social and economic impacts, such as homelessness (NHC, 67\%; WFO, 25\%, PO, 67\%; BR, 40\%), and vulnerability stemming from human characteristics such as age or disability (Lazrus et al. 2012) (NHC, 67\%; WFO, 25\%; PO, 33\%; BR, 40\%).

\section{7) UNCERTAINTY IN FORECAST AND WARNING PROCESSES}

Members of the different professional groups discussed the role of uncertainty in the hurricane forecast and warning system in diverse ways. NHC and WFO forecasters discussed tools for estimating forecast 
uncertainty such as wind speed probability modeling or forecast model spread, neither of which was mentioned by public officials or broadcasters. One way that forecasters discussed using these tools is by waiting and watching if there is large spread among model forecasts and sufficient time before landfall, to reduce uncertainties before deciding to issue a watch or warning. They also discussed how information about past forecast errors is used to improve forecasts and to estimate and convey uncertainty in NWS forecast products such as the cone graphic (which depicts uncertainty in forecast track) and the wind speed probabilities.

The forecasters also mentioned planned or potential future improvements to the tools they use to estimate and depict forecast uncertainty, for example, to incorporate situation-dependent forecast errors into probability products or to develop an algorithm to delineate watch and warning endpoints using probability forecasts. In addition, they mentioned informal methods for managing and communicating forecast uncertainty. For example, an NHC forecaster said that "we convey [the uncertainty] in an indirect sense by just telling people not to focus on the exact track" (NHC2), and several NHC and WFO forecasters described how they convey forecast uncertainty in their forecast discussion products or in briefings.

Most of the broadcasters' discussions of uncertainty focused around how they convey uncertainty, for example, using the NHC cone graphic or their own variant. As one broadcaster explained, they can also communicate forecast uncertainty (or certainty) more informally: "There is a lot of verbal cues that I can do. And I think those are important too, and actually I mean people will tell you that they can read my body language and they can determine how serious the threat is based on my tone of voice and my body language alone ... because people have been watching me for years" (BR1). This same broadcaster said that uncertainty "is of course a very important question these days, and I know that myself and others are trying to figure a way to better convey uncertainty to the viewing and listening audience." However, not all broadcasters had the same view of hurricane risk communication in the face of uncertainty. For example, when asked whether he communicates uncertainty in his broadcasts, another broadcaster said, "[I] try not to.... When we get on the air we need to be pretty darn certain that what we are disseminating is fact and not fiction" (BR4).

Public officials' discussions of uncertainty focused more on how it interacts with their protective decisionmaking. As one public official explained, "Uncertainty is everything we do. And everything we do and actions we take is ... using that uncertainty in trying to make the best decisions we can" (PO1). To manage forecast uncertainties, public officials consult with $\mathrm{NHC}$ and WFOs, and they incorporate NHC forecast data into their planning using software tools such as HURREVAC. One public official noted that they do not have problems with the NWS information, and it is timely, but "the problem is that it is, there is a lot of uncertainty" (PO3). This same public official explained the value of conversations with trusted forecasters: "We have a very good relationship with the National Hurricane Center, so when we have uncertainties like that I mean we really have some good conversations with them about, listen this is what we are thinking ... and based on the information you are providing us, is there anything else or you know you have concerns about, maybe things that we are thinking of doing or you know, we just try to kind of chat that out with the subject matter experts" (PO3). To make decisions, public officials "look at all of the facts, you look at probabilities and likelihoods and potential impacts, and ultimately you just, you make the best decision with the information that you have." (PO3)

All of the professional groups talked about the use of scenarios to manage and communicate forecast uncertainty. For example, an NHC forecaster explained how "we can talk about alternate scenarios, things that might happen. If - if the forecast is going to be wrong, here's how-here's the direction it might go wrong in" (NHC4). A public official described accounting for uncertainty by using the "worst case.... If you go logical worst case scenario, hopefully you are beneath that. The logical worst case doesn't mean throw the kitchen sink every time, it means throw what looks appropriate, it seems like slightly larger than what you are looking at" (PO1). Another public official said that "you have to factor that in when you get these warnings and watches and everything, that this isn't an exact science but it is a lot better than it used to be.... And so if the worst case scenario is that you are going to take a direct hit from a category 4 or 5 storm, then you had better prepare for that. And you know one of the things that is real critical sometimes is well, that is going to hurt us budget-wise" (PO5). As this quote suggests, managing uncertainty in the hurricane warning system involves trade-offs between the benefits and costs of warning people or taking protective action.

As discussed in section $3 \mathrm{a}(3)$, many of the professionals discussed erring on the side of caution, especially when lives are at risk [see also Morss et al. (2015) on the flash flood warning system]. However, a broadcaster explained that one can go too far in using precautionary scenarios: "There are extremes to conveying uncertainty and that is one of the problems here in 
Dendrogram using Average Linkage (Between Groups)

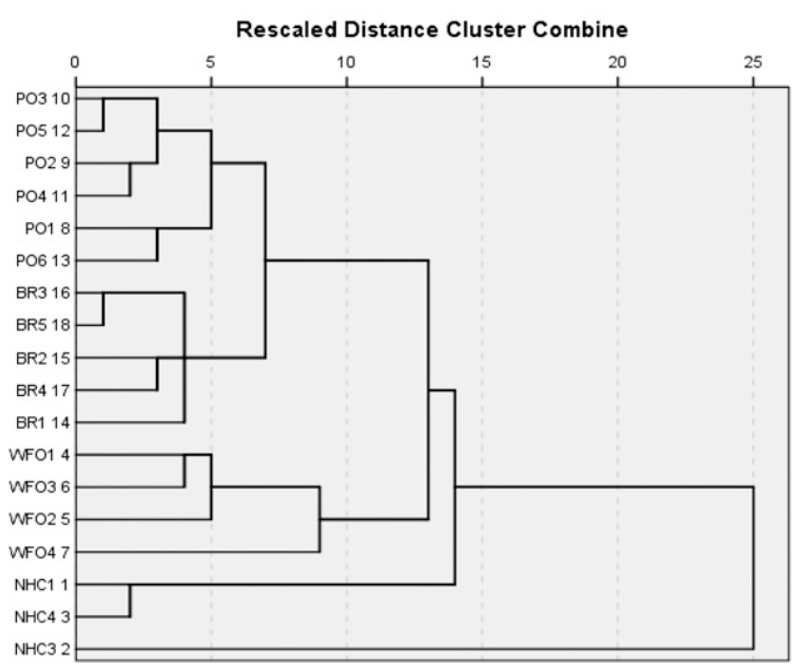

FIG. 5. Hamann similarity clusters showing the similarity of individual professionals based on coded interview content.

Miami, where you know you could only give people so many different scenarios of what might happen in a storm or worse yet a serious hurricane ... how to not convey that message well is by continuing to expand on scenarios that are highly unlikely to unfold, and as the likelihood of those scenarios continues to diminish you are still portraying those scenarios on television even though the likelihood of them occurring are slim to none. I think that is a disservice" (BR1). Differing interpretations of what is appropriate and precautionary as hurricanes evolve deserve closer attention.

As illustrated by professionals' remarks regarding uncertainty estimation, depiction, communication, and management, the representation and interpretation of uncertainty in hurricane forecast and warning decisions remains a serious challenge.

\section{b. Similarities among professionals: Cluster analysis}

Figure 5 shows the dendrogram resulting from our Hamann similarity calculations and cluster analysis. As expected, to the extent that their expressions of hurricane forecast and warning concepts represent their mental models, the mental models of professionals are most similar by professional role: public officials most resemble one another, broadcasters most resemble one another, and WFO forecasters most resemble one another. The one exception is the NHC forecasters: of the three who completed full interviews, one of them (NHC3) stands out as being the most different from all of the other interviewees, primarily because he mentioned many more concepts. This suggests high variability in knowledge and perceptions even among those forecasters with the most hurricane expertise. Given the small number of professionals involved in the forecast and warning system for any given hurricane, it follows from the descriptive analyses and clustering results that the departure or absence of even a single forecaster may have a substantial effect on the total expertise and experience represented in the system.

NHC and WFO forecasters work within the same organization (NWS), and all have formal educational training in meteorology or atmospheric science (section 2a). Most of the broadcasters, unlike the public officials, also have some formal education in meteorology and interact with weather forecasts as a primary part of their job every day. However, according to the clustering in Fig. 5, public officials are more like broadcasters than they are like WFO forecasters, and WFO forecasters are more similar to public officials and broadcasters than they are to NHC forecasters. This suggests that NHC forecasters, with their in-depth, focused expertise in hurricanes and their role in a national NWS center, have mental models that differ in some important ways from those of the WFO forecasters, public officials, and broadcasters, whose jobs are less specialized and who all have a more local focus on the Miami area (cf. Demuth et al. 2012). This is potentially important for hurricane risk communication because, when a hurricane threatens U.S. landfall, NHC is often the major NWS point of contact for those outside NWS.

\section{Discussion and conclusions}

These results suggest opportunities for improving the hurricane forecast and warning system in three main regards. First, as the cluster analysis suggests, especially in the distinctiveness of one forecaster from the others, the system would likely be made more robust in the long term by cultivating a better shared understanding of the forecast and warning system as described here among those with the greatest scientific and forecasting hurricane expertise, though this would be resource intensive. Second, although the NHC and WFOs do a lot of effective and much appreciated work to communicate and coordinate with public officials and media, further effort may be warranted to improve coordination within the system, with an eye toward creating a more streamlined and effective product portfolio. For example, the system model suggests there has been a proliferation of NWS products, and the interviews suggest that many forecast and warning products are not salient or readily useable other than to their producers. Thus, improved coordination among warning system professionals should increase familiarity with others' products and information uses and needs. Third, presentation and management of uncertainty 
remains challenging in the hurricane forecast and warning system, despite some concerted efforts to understand and improve on this. Forecasters themselves appear to believe their efforts to communicate risks and uncertainty are not well understood or used.

As illustrated in the results, further technical advances in forecasting and warnings are under development; less evident is timely, effective incorporation of feedback from the audiences for forecast and warning information, to ensure that products are meaningful to users and that forecast (un)certainty is communicated well. Members of the hydrometeorological community often assume that improving a forecast or warning, in and of itself, will enhance its value. A common corollary to this assumption is that the best way to increase forecast value is to improve forecast accuracy_as measured using verification metrics relevant to meteorology but not necessarily to users (Morss et al. 2008b)_or simply to provide more forecast information. Yet, ample evidence suggests these premises do not always hold (e.g., Murphy 1993; Roebber 1996; Morss 2005). For example, recent hurricanes such as Katrina and Sandy resulted in significant loss of life and devastating damage despite accurate forecasts and timely warnings (Knabb et al. 2005; NOAA 2013). Improving forecast and warning products based on formally incorporated feedback from users, including other professionals in the forecast and warning system with a better understanding of the social and behavioral contexts of warning uses, may help address such disconnects.

Earlier research has shown that effective warning systems consist of three main subsystems: detection, management, and response subsystems (Mileti and Sorensen 1990, see especially their Fig. 2.1). This is consistent with our findings (Fig. 1), with the caveat that our interview protocols focused on forecasts and warnings as decision support and may not fully reflect the response subsystem. The attenuated link between accurate forecasts and responsive behaviors that is nevertheless evident may stem in part from how the hydrometeorological community currently operates. Weather researchers and forecasters focus on analysis of hydrometeorological data, hydrometeorological modeling, and forecast production and dissemination as the primary functions of their professional responsibilities. Although they are interested in communicating forecasts in ways that aid effective decisionmaking, the expertise and data necessary to support this has been lacking, historically (e.g., Broad et al. 2007; Demuth et al. 2012; Morss et al. 2008b; NRC 2006a; NRC 2010). This may significantly reduce their ability to provide information that effectively informs and encourages appropriate decision-making and self-protective action in extreme weather events (e.g., Morss et al. 2005; Pielke 1999; Stern 1999). Thus, routine empirical testing and evaluation of individual forecast and warning products and of the full product portfolio with sample users appears warranted, building on the evaluative research that has been carried out to date (e.g., Baker 1995; Meyer et al. 2013; Morss et al. 2016; Wu et al. 2014, 2015).

Lack of detail in some of the professionals' discussions of social impacts may be a result of the forecaster-centric model development, but together with the significant variability between forecasters as shown in the similarity analyses and Fig. 2, this suggests potential issues to consider as the NWS moves down the path of developing and implementing impact-based warnings. Most importantly, meteorologists may benefit from additional nonmeteorological expertise, which is required to effectively design impact-oriented warning content and strategies. Further exploration of this area will help the NWS evolve its policies and warning products in ways that work with its partners to help protect the public.

Interviewees described both formal and informal approaches to communicating uncertainty, which they see as a critical element of forecast and warning decisionmaking. Consistent with findings from Demuth et al. (2012), the interviews suggest a tendency for emergency managers to account for uncertainty by taking a conservative, worst-case-scenario approach in the interest of protecting their publics, although they recognize the potential downsides of overwarning. These results suggest that the uncoordinated formal and informal precautionary treatment of uncertainty in multiple parts of the system may be accreting in unintended ways.

The mental models methodology applied in this research facilitated the development of a thick description of the hurricane forecast and warning system, but was labor intensive. In hindsight, a simpler, less detailed approach might have revealed some of the results reported here. However, the mental models approach produced a nuanced characterization of the system and decision-making within it. The separate interviews with broadcasters and public officials as well as forecasters from both the NHC and WFO illustrated the depth and variability in professionals' perspectives, as well as the complexity and characteristics of hurricane forecast and warning information development, production, dissemination, and use. The analysis revealed commonalities among professionals that support a successful partnership, as well as important differences among professionals in different roles. Although their counterparts in other areas at risk of hurricanes might be more heterogeneous and less experienced, we expect that they would exhibit similar commonalities and differences. We also found significant variability between professionals within the same group, suggesting that system performance may vary depending on the involvement 
of a few individuals, at least in this instance where the group represents the highest level of expertise nationally. As implemented, the mental models methodology should also enable comparisons with other forecast and warning systems, including in other hurricanevulnerable areas.

Finally, no picture of the hurricane forecast and warning system would be complete without a similar analysis of the perspectives of intended end audience for forecast and warnings: the public. Such an examination is the topic of companion pieces in which this decision model informs analysis of data from mental models interviews and survey research with members of the Miami public (Lazo et al. 2015; A. Bostrom et al. 2016, unpublished manuscript; cf. Morss et al. 2016).

Acknowledgments. The generosity of the professionals who participated in this study for sharing their time and expertise is gratefully acknowledged, as is funding from the U.S. National Science Foundation (NSF 0729302 and 0729511), the helpful comments of three anonymous reviewers, and invaluable research assistance from Nina Tantraphol, Keisha Childers, Ross Gilliland, and Risa Pavia. Partial support for this research came from Eunice Kennedy Shriver National Institute of Child Health and Human Development research infrastructure Grant R24 HD042828 to the Center for Studies in Demography and Ecology at the University of Washington.

\section{REFERENCES}

Anthony, K. E., K. R. Cowden-Hodgson, H. D. O'Hair, R. L. Heath, and G. M. Eosco, 2014: Complexities in communication and collaboration in the hurricane warning system. Commun. Stud., 65, 468-483, doi:10.1080/10510974.2014.957785.

Baker, E. J., 1995: Public response to hurricane probability forecasts. Prof. Geogr., 47, 137-147, doi:10.1111/j.0033-0124.1995.00137.x.

Bostrom, A., B. Fischhoff, and M. G. Morgan, 1992: Characterizing mental models of hazardous processes: A methodology and an application to radon. J. Soc. Issues, 48, 85-100, doi:10.1111/ j.1540-4560.1992.tb01946.x.

Broad, K., A. Leiserowitz, J. Weinkle, and M. Steketee, 2007: Misinterpretations of the "cone of uncertainty" in Florida during the 2004 hurricane season. Bull. Amer. Meteor. Soc., 88, 651-657, doi:10.1175/BAMS-88-5-651.

Bruine de Bruin, W., and A. Bostrom, 2013: Assessing what to address in science communication. Proc. Natl. Acad. Sci. USA, 110, 14 062-14 068, doi:10.1073/pnas.1212729110.

Brunet, G., B. Golding, T. Jung, N. Gordon, H. Goesslig, F. Vitart, A. Robertson, S. Jones, and P. Ruti, 2015: The World Weather Research Programme: A 10-year vision. WMO Bull., 64 (1), 16-19.

Clemen, R. T., and T. Reilly, 2001: Making Hard Decisions with Decision Tools. Cengage Press, 752 pp.

Dash, N., and H. Gladwin, 2007: Evacuation decision making and behavioral responses: Individual and household. Nat. Hazards Rev., 8, 69-77, doi:10.1061/(ASCE)1527-6988(2007)8:3(69).
Demuth, J. L., R. E. Morss, B. H. Morrow, and J. K. Lazo, 2012: Creation and communication of hurricane risk information. Bull. Amer. Meteor. Soc., 93, 1133-1145, doi:10.1175/BAMS-D-11-00150.1.

Doswell, C. A., III, 2004: Weather forecasting by humansHeuristics and decision making. Wea. Forecasting, 19, 11151126, doi:10.1175/WAF-821.1.

Downton, M. W., R. E. Morss, O. V. Wilhelmi, E. Gruntfest, and M. L. Higgins, 2005: Interactions between scientific uncertainty and flood management decisions: Two case studies in Colorado. Global Environ. Change, 6B, 134-146, doi:10.1016/ j.hazards.2006.05.003.

Eisenman, D. P., K. M. Cordasco, S. Asch, J. F. Golden, and D. Glik, 2007: Disaster planning and risk communication with vulnerable communities: Lessons from Hurricane Katrina. Amer. J. Public Health, 97, S109-S115, doi:10.2105/ AJPH.2005.084335.

Freebairn, J. W., and J. W. Zillman, 2002: Economic benefits of meteorological services. Meteor. Appl., 9, 33-44, doi:10.1017/ S1350482702001044.

Hohenemser, C., R. W. Kates, and P. Slovic, 1983: The nature of technological hazard. Science, 220, 378-384, doi:10.1126/ science.6836279.

Holley, J. W., and J. P. Guilford, 1964: A note on the G index of agreement. Educ. Psychol. Meas., 24, 749-753, doi:10.1177/ 001316446402400402.

Howard, R. A., and A. E. Abbas, 2016: Foundations of Decision Analysis. Pearson Education Ltd., 832 pp.

Huang, S. K., M. K. Lindell, C. S. Prater, H. C. Wu, and L. K. Siebeneck, 2012: Household evacuation decision making in response to Hurricane Ike. Nat. Hazards Rev., 13, 283-296, doi:10.1061/(ASCE)NH.1527-6996.0000074.

,$- \ldots$, and -2016 : Who leaves and who stays? A review and statistical meta-analysis of hurricane evacuation studies. Environ. Behav., doi:10.1177/0013916515578485, in press.

Joslyn, S. L., and J. E. LeClerc, 2012: Uncertainty forecasts improve weather-related decisions and attenuate the effects of forecast error. J. Exp. Psychol. Appl., 18, 126, doi:10.1037/a0025185.

Katz, R. W., and A. H. Murphy, Eds., 1997: Economic Value of Weather and Climate Forecasts. Cambridge University Press, $240 \mathrm{pp}$.

Knabb, R. R., J. R. Rhome, and D. P. Brown, 2005: Tropical Cyclone Report: Hurricane Katrina: 23-30 August 2005. NOAA/NWS/National Hurricane Center, accessed 1 November 2012. [Available online at http://www.nhc.noaa.gov/ data/tcr/AL122005_Katrina.pdf.]

Lazo, J. K., 2010: The costs and losses of integrating social sciences and meteorology. Wea. Climate Soc., 2, 171-173, doi:10.1175/ 2010WCAS1086.1.

—, D. M. Waldman, B. H. Morrow, and J. A. Thacher, 2010: Household evacuation decision making and the benefits of improved hurricane forecasting: developing a framework for assessment. Wea. Forecasting, 25, 207-219, doi:10.1175/ 2009WAF2222310.1.

_ A. Bostrom, R. E. Morss, J. L. Demuth, and H. Lazrus, 2015: Factors affecting hurricane evacuation intentions. Risk Anal., 35, 1837-1857, doi:10.1111/risa.12407.

Lazrus, H., B. H. Morrow, R. E. Morss, and J. K. Lazo, 2012: Vulnerability beyond stereotypes: Context and agency in hurricane risk communication. Wea. Climate Soc., 4, 103-109, doi:10.1175/WCAS-D-12-00015.1.

_ R. E. Morss, J. L. Demuth, J. K. Lazo, and A. Bostrom, 2016: "Know what to do if you encounter a flash flood": Mental models analysis for improving flash flood risk communication 
and public decision making. Risk Anal., doi:10.1111/ risa. 12480 , in press.

Letson, D. S., D. Sutter, and J. Lazo, 2007: Economic value of hurricane forecasts: An overview and research needs. Nat. Hazards Rev., 8, 78-86, doi:10.1061/(ASCE)1527-6988(2007)8:3(78).

Meyer, R., K. Broad, B. Orlove, and N. Petrovic, 2013: Dynamic simulation as an approach to understanding hurricane risk response: Insights from the Stormview lab. Risk Anal., 33, 1532-1552, doi:10.1111/j.1539-6924.2012.01935.x.

Mileti, D. S., and J. H. Sorensen, 1990: Communication of emergency public warnings: A social science perspective and stateof-the-art assessment. Rep. ORNL-6609, Oak Ridge National Laboratory, 160 pp., doi:10.2172/6137387.

Morgan, M. G., 1993: Risk analysis and management. Sci. Amer. 269, 32-41, doi:10.1038/scientificamerican0793-32.

—, B. Fischhoff, A. Bostrom, and C. J. Atman, 2002: Risk Communication: A Mental Models Approach. Cambridge University Press, 366 pp.

Morrow, B. H., and J. K. Lazo, 2014: Coastal emergency manager's preferences for storm surge information. J. Emerg. Manag., 12, 153-160, doi:10.5055/jem.2014.0169.

_,- J. Rhome, and J. Feyen, 2015: Improving storm surge risk communication: Stakeholder perspectives. Bull. Amer. Meteor. Soc., 96, 35-48, doi:10.1175/BAMS-D-13-00197.1.

Morss, R. E., 2005: Problem definition in atmospheric science public policy: The example of observing-system design for weather prediction. Bull. Amer. Meteor. Soc., 86, 181-191, doi:10.1175/BAMS-86-2-181.

—_, and M. H. Hayden, 2010: Storm surge and "certain death": Interviews with Texas coastal residents following Hurricane Ike. Wea. Climate Soc., 2, 174-189, doi:10.1175/ 2010WCAS1041.1.

_- O. V. Wilhelmi, M. W. Downton, and E. Gruntfest, 2005: Flood risk, uncertainty, and scientific information for decision-making: Lessons from an interdisciplinary project. Bull. Amer. Meteor. Soc., 86, 1593-1601, doi:10.1175/ BAMS-86-11-1593.

_ - J. L. Demuth, and J. K. Lazo, 2008a: Communicating uncertainty in weather forecasts: A survey of the U.S. public. Wea. Forecasting, 23, 974-991, doi:10.1175/2008WAF2007088.1.

— J. K. Lazo, B. G. Brown, H. E. Brooks, P. T. Ganderton, and B. N. Mills, 2008b: Societal and economic research and applications priorities for the North American THORPEX program. Bull. Amer. Meteor. Soc., 89, 335-346, doi:10.1175/ BAMS-89-3-335.

_ J. D. Demuth, A. Bostrom, J. K. Lazo, and H. Lazrus, 2015: Flash flood risks and warning decisions: A mental models study of forecasters, public officials, and media broadcasters in Boulder, Colorado. Risk Anal., 35, 2009-2028, doi:10.1111/risa.12403.

_ J. L. Demuth, J. K. Lazo, K. Dickinson, H. Lazrus, and B. H. Morrow, 2016: Understanding public hurricane evacuation decisions and responses to forecast and warning messages. Wea. Forecasting, doi:10.1175/WAF-D-15-0066.1, in press.

Murphy, A. H., 1993: What is a good forecast? An essay on the nature of goodness in weather forecasting. Wea. Forecasting, 8, 281-293, doi:10.1175/1520-0434(1993)008<0281:WIAGFA $>2.0 . C O ; 2$.

—, S. Lichtenstein, B. Fischhoff, and R. L. Winkler, 1980: Misinterpretations of precipitation probability forecasts. Bull. Amer. Meteor. Soc., 61, 695-701, doi:10.1175/1520-0477(1980)061<0695: $\mathrm{MOPPF}>2.0 . \mathrm{CO} ; 2$.

Mylne, K. R., 2002: Decision-making from probability forecasts based on forecast value. Meteor. Appl., 9, 307-315, doi:10.1017/S1350482702003043.
NOAA, 2011: NOAA's National Weather Service Strategic Plan: Building a Weather-Ready Nation. Accessed 11 January 2016. [Available online at http://www.nws.noaa.gov/com/ weatherreadynation/files/strategic_plan.pdf.]

, 2013: Service assessment: Hurricane/Post-Tropical Cyclone Sandy, October 22-29, 2012. NOAA/NWS Doc., 66 pp. [Available online at http://www.nws.noaa.gov/os/assessments/ pdfs/Sandy13.pdf.]

NRC, 2006a: Completing the Forecast: Characterizing and Communicating Uncertainty for Better Decisions Using Weather and Climate Forecasts. National Academies Press, 124 pp., doi:10.17226/11699.

_ 2006b: Facing Hazards and Disasters: Understanding Human Dimensions. National Academies Press, 408 pp., doi:10.17226/ 11671.

- 2010: When Weather Matters: Science and Service to Meet Critical Social Needs. National Academies Press, 198 pp., doi:10.17226/12888.

Pielke, R. A., Jr., 1997: Reframing the U.S. hurricane problem. Soc. Nat. Resour., 10, 485-499, doi:10.1080/08941929709381046.

1999: Who decides? Forecasts and responsibilities in the 1997 Red River flood. Amer. Behav. Sci. Rev., 7, 83-101, doi:10.1016/S1068-8595(00)80012-4.

Rappaport, E. N., 2014: Fatalities in the United States from Atlantic tropical cyclones: New data and interpretation. Bull. Amer. Meteor. Soc., 95, 341-346, doi:10.1175/BAMS-D-12-00074.1.

Rice, L. L., 2014: An analysis of public perception and response to Hurricane Sandy. M.S. thesis, Dept. of Geography, Environment and Planning, University of South Florida, 80 pp. [Available online at http://scholarcommons.usf.edu/etd/5114.]

Roebber, P. J., 1996: The complex relationship between forecast skill and forecast value: A real-world analysis. Wea. Forecasting, 11, 544-559, doi:10.1175/1520-0434(1996)011<0544: TCRBFS $>2.0 . \mathrm{CO} ; 2$.

Sherman-Morris, K., J. Senkbeil, and R. Carver, 2011: Who's Googling what? What internet searches reveal about hurricane information seeking. Bull. Amer. Meteor. Soc., 92, 975985, doi:10.1175/2011BAMS3053.1.

Stern, P. C., 1999: Making Climate Forecasts Matter. National Academies Press, 192 pp., doi:10.17226/6370.

Stewart, T. R., P. J. Roebber, and L. F. Bosart, 1997: The importance of the task in analyzing expert judgment. Organ. Behav. Hum. Decis. Processes, 69, 205-219, doi:10.1006/ obhd.1997.2682.

Tierney, K. J., 2014: The Social Roots of Risk: Producing Disasters, Promoting Resilience. Stanford University Press, 320 pp.

—, M. K. Lindell, and R. W. Perry, 2001: Facing the Unexpected: Disaster Preparedness and Response in the United States. National Academies Press, 320 pp., doi:10.17226/9834.

Wolshon, B., V. Dixit, and J. Renne, 2013: Special issue on interdisciplinary and multimodal nature of evacuations: Nexus of research and practice. Nat. Hazards Rev., 14, 149-150, doi:10.1061/(ASCE)NH.1527-6996.0000115.

Wood, M. D., A. Bostrom, T. Bridges, and I. Linkov, 2012: Cognitive mapping tools: Review and risk management needs. Risk Anal., 32, 1333-1348, doi:10.1111/j.1539-6924.2011.01767.x.

Wu, H.-C., M. K. Lindell, C. S. Prater, and C. D. Samuelson, 2014: Effects of track and threat information on judgments of hurricane strike probability. Risk Anal., 34, 1025-1039, doi:10.1111/ risa.12128.

,-- , and -2015 : Process tracing analysis of hurricane information displays. Risk Anal., 35, 2202-2220, doi:10.1111/ risa.12423. 